\title{
Percepção da família de adolescentes sobre o cuidado no contexto do consumo de drogas
}

\author{
Edite Lago da Silva Sena ${ }^{1}$, \\ Vanessa Thamyris Carvalho dos Santos ${ }^{2}$, \\ Lucas Queiroz Subrinho ${ }^{3}$, \\ Patrícia Anjos Lima de Carvalho ${ }^{4}$
}

\section{RESUMO}

O estudo teve como objetivo compreender como o cuidado relacionado ao consumo de drogas é percebido pelos familiares de estudantes do ensino médio, à luz do pensamento de Maurice Merleau-Ponty. Realizado no primeiro semestre de 2015, no domicílio de 14 familiares de estudantes de escola pública no interior da Bahia, Brasil, por meio de entrevista fenomenológica. As descrições vivenciais produzidas foram submetidas à técnica Analítica da Ambiguidade. Os resultados revelam a necessidade de a família e a escola participarem do cuidado relacionado ao consumo de drogas, com vistas à construção coletiva de projetos de vida mais saudáveis. Ao mesmo tempo, os dados apontam a importância de fortalecer a política de redução de danos. O estudo contrasta a visão objetivista em relação ao tema e mostra a importância das ações intersetoriais para o cuidado humano mais efetivo no contexto do consumo de drogas.

Descritores: Drogas Ilícitas; Família; Adolescente; Filosofia em Enfermagem.

\footnotetext{
${ }^{1}$ Enfermeira, Doutora em Enfermagem. Professor Titular da Universidade Estadual do Sudoeste da Bahia, Campus Jequié. Jequié, BA, Brasil. E-mail: editelago@gmail.com.

2 Enfermeira, Mestre em Enfermagem e Saúde. Discente do Programa de Pós-Graduação em Enfermagem e Saúde, nível Doutorado, da Universidade Estadual do Sudoeste da Bahia, Campus Jequié. Jequié, BA, Brasil. E-mail: nessathamyris@hotmail.com.

${ }^{3}$ Enfermeiro, Mestre em Enfermagem e Saúde. Jequié, BA, Brasil. E-mail: lucas.q.subrinho@gmail.com.

${ }^{4}$ Enfermeira, Mestre em Enfermagem e Saúde. Discente do Programa de Pós-Graduação em Enfermagem e Saúde, nível Doutorado, da Universidade Estadual do Sudoeste da Bahia, Campus Jequié. Jequié, BA, Brasil. E-mail: patricia.anjos3@gmail.com.
}

\section{Como citar esse artigo:}

Sena ELS, Santos VTC, Subrinho LQ, Carvalho PAL. Percepção da família de adolescentes sobre o cuidado no contexto do consumo de drogas. Rev. Eletr. Enf. [Internet]. 2018 [acesso em: ];20:v20a20. Disponível em: https://doi.org/10.5216/ree.v20.48274. 


\section{INTRODUÇÃO}

Ao abordarmos a questão do consumo de drogas, é importante destacar que os adolescentes têm sido considerados o grupo mais vulnerável, visto que essa fase da vida é marcada pela curiosidade em experimentar o novo e um sentimento de onipotência(1). Além disso, nessa fase, as pessoas valorizam mais os comportamentos dos grupos sociais em que estão inseridos, o ambiente familiar pode favorecer o consumo de drogas, quando os próprios familiares realizam tal prática, como também quando os adolescentes têm relações conflituosas com os pais ${ }^{(2)}$.

A literatura aponta também que a escola onde os adolescentes estão inseridos pode constituir-se um local de vulnerabilidade ao consumo de drogas, uma vez que nela os adolescentes podem entrar em contato com grupos de amigos que as consomem ${ }^{(3)}$. No entanto, também pode constituir-se como local de proteção quando, por exemplo, propõe-se a realizar atividades educativas com a temática ${ }^{(4)}$. Porém, nem sempre os educadores das escolas se sentem responsáveis pelo cuidado no contexto do consumo de drogas ${ }^{(5)}$.

Essa realidade que também se estendia ao campo da saúde estava atrelada ao fato da questão do consumo de drogas ainda ser visto como um problema de segurança pública, o que também contribuiu para a estigmatização das pessoas que não desejavam ou não conseguiam parar de consumir drogas, ao mesmo tempo em que impulsionou importantes mudanças no campo da saúde no que se refere às Políticas de Saúde Mental no Brasil, relacionadas à questão, que passaram a ser pensadas segundo a lógica da Estratégia de Redução de Danos $(\mathrm{RD})^{(6)}$. Essa estratégia preconiza que o cuidado no contexto do consumo de drogas requer o envolvimento dos diferentes atores sociais, entre os quais destaca-se a família ${ }^{(7)}$.

Estudos têm revelado a família tanto como fator de vulnerabilidade ${ }^{(3,8)}$ quanto de proteção no que refere ao consumo de drogas ${ }^{(9-10)}$. Apesar dos estudos sinalizarem a ambiguidade presente na relação da família com o consumo de drogas, eles reforçam a visão objetivista na medida em que buscam explicações causais para o fenômeno.

No entanto, nossa vivência no desenvolvimento de pesquisas fenomenológicas nos fez ver que ela abre possibilidades à descrição e compreensão de vivências e sentidos que transcendem na relação mundo-homemcoisa e, nesse sentido, a aproximação com famílias vulneráveis ao consumo de drogas pode desvelar perfis que confirmam a incompletude das explicações da ciência positivista e evidenciam a necessidade de desconstrução da tese que atrela o cuidado à proibição do consumo de drogas.

Desse modo, o estudo teve como objetivo compreender como o cuidado relacionado ao consumo de drogas é percebido pelos familiares de estudantes do ensino médio, à luz do pensamento de Maurice Merleau-Ponty. A presente pesquisa se faz relevante para produção do conhecimento, entre outros aspectos, na medida em que questiona algumas teses que vêm sendo defendidas em torno do assunto e abre possibilidade à percepção do cuidado no contexto do consumo de drogas na perspectiva dialógica e intersubjetiva.

\section{MÉTODO}

Estudo fundamentado na fenomenologia de Maurice Merleau-Ponty ${ }^{(11)}$, que se ocupa em discorrer, especialmente, sobre a ambiguidade que envolve a experiência da percepção humana, a qual constitui em uma experiência intercorporal cuja dinâmica sempre revela diferentes perfis, que envolvem a coexistência de duas 
dimensões constitutivas do ser humano: a sensível e a sociocultural(11). Segundo o autor, a dimensão sensível tem a ver com os sentimentos, com algo que é comum a todos os seres humanos, e a sociocultural, construída nas relações sociais no contexto da historicidade.

Para melhor ambientar-nos e também para que os funcionários e estudantes pudessem nos conhecer, permanecemos em uma escola estadual do interior da Bahia, Brasil, durante três semanas antes de iniciar a coleta de informações. Inicialmente, realizamos uma reunião com a coordenação da escola para esclarecer a proposta do estudo; em seguida, divulgamos a realização de uma atividade voltada à construção de redes sociais, solidárias, de promoção da vida e de mobilização de recursos e competências individuais, familiares e comunitárias, a Terapia Comunitária Integrativa $(\mathrm{TCl})^{(12)}$.

A TCI foi planejada visando oportunizar a escuta do sofrimento e da sabedoria dos estudantes, favorecer o acolhimento e aproximação com o grupo, uma vez que na mesma sessão é possível mostrar aos participantes que eles têm problemas e soluções, bem como por não exigir a continuidade da ação(12).

Dos 50 estudantes que participaram da roda de $\mathrm{TCl}, 30$ informaram um número de telefone para contato com o seu familiar responsável. Ao entrarmos em contato, agendamos a entrevista em domicílio dos familiares que se dispuseram a participar, considerando a resistência dos mesmos quanto a se deslocar até a escola.

Assim, a pesquisa foi desenvolvida com 14 familiares que atenderam aos seguintes critérios: ter idade acima de 18 anos; ser familiar de estudante regularmente matriculado do 1 을 a 3 o ano do ensino médio onde aconteceu a roda de $\mathrm{TCl}$; ser responsável legal pelo estudante.

Por tratar-se de um estudo que utiliza entrevista fenomenológica, e é baseado na fenomenologia de Maurice Merleau-Ponty, não há uma quantidade de participantes pré-estabelecida, até porque isso não é relevante mas, sim, a profundidade da discussão do que se desvela. Essa característica permitirá, inclusive, fazer generalizações, pois se busca a descrição do mundo sensível, que é similar a todos os seres humanos. Essa modalidade de estudo atenta para a coexistência, pois consideramos que o mundo não existe só para nós, mas para tudo que nele acena, e, assim, o mundo dos sentimentos é potencialmente vivido por todos ${ }^{(13)}$.

Para a produção das descrições vivenciais foram realizadas entrevistas fenomenológicas, que se propõem a compreender o fenômeno na perspectiva de quem está vivenciando e significando, tal como ocorre na experiência vivida. Esse tipo de entrevista deve ser disparado por uma a três questões norteadoras ${ }^{(14)}$. No caso deste estudo, utilizamos a seguinte questão: Como você compreende o cuidado relacionado ao consumo de drogas?

As entrevistas tiveram duração média de 30 minutos, no período de março a maio de 2015. As descrições vivenciais resultantes das entrevistas foram submetidas à técnica Analítica da Ambiguidade ${ }^{(15)}$ por meio da qual fizemos leituras em profundidade do material. Na leitura do material empírico sentimos algo com o qual nos identificamos e "somos capturados por uma experiência inédita que nos faz trazer para o presente um mundo que nos é estranho, mas que, ao mesmo tempo, parece-nos familiar"(15). Trata-se da presentificação de uma vivência criativa em suspensão de uma tese socialmente constituída, que aprisiona o sujeito a uma visão objetivista das coisas. Em seguida, procedemos à categorização.

O estudo atendeu aos preceitos éticos das normas brasileiras para pesquisas científicas com seres humanos. O projeto foi aprovado pelo Comitê de Ética em Pesquisa da Universidade Estadual do Sudoeste da 
Bahia (CEP/UESB), segundo o parecer no 989.705/2015. Todos os participantes assinaram o Termo de Consentimento Livre e Esclarecido (TCLE) e para resguardar o anonimato dos mesmos os identificamos com codinomes de deuses gregos.

\section{RESULTADOS E DISCUSSÃO}

O processo de compreensão das descrições vivenciais dos participantes resultou nas categorias temáticas, dentre elas, discutiremos neste artigo as seguintes: Expressão sociocultural diante do fenômeno "consumo de drogas"; Expressão sensível diante do fenômeno "consumo de drogas".

\section{Expressão sociocultural diante do fenômeno "consumo de drogas"}

A formulação desta categoria foi inspirada no pensamento de Merleau-Ponty quando discorre sobre a influência sociocultural na construção histórica do ser humano ${ }^{(11)}$. O filósofo veio trazer uma nova visão de mundo ao contrastar o naturalismo científico e o subjetivismo cartesiano. Com isso, recusa terminantemente as dicotomias: alma-corpo, consciência-mundo, homem-natureza, sujeito-objeto; propõe-se a desconstruir teses na perspectiva de compreender o vivido, em vez de explicá-lo, uma vez que para a fenomenologia toda explicação é insuficiente ${ }^{(11,13)}$

As descrições dos familiares participantes sobre o cuidado relacionado ao consumo de drogas revela um olhar objetivista em relação à substância, resultante da própria construção socioantropológica, que contribui para a formulação de teses que são incorporadas ao imaginário social, conforme podemos observar a seguir:

O consumo de drogas? Destruição, destruindo as famílias, destruindo quem faz uso (Apolo).

[...] Eu creio que para mim é destruição porque, infelizmente, o fim da droga só é a morte e a cadeia, não é? (Artémis)

[...] Destruição, destrói ele próprio, a família. (Eros)

As drogas estão matando com tudo [...] (Zeus).

Tantas crianças e adolescentes se perdendo nesse mundo das drogas! [...] (Ares)

As teses desveladas são reflexos da inserção humana no mundo sociocultural ao longo do tempo, o que envolve crenças, costumes e valores. Muitas vezes, não chegamos a refletir sobre determinado fenômeno social que se impõe a nós, mas o repetimos habitualmente conforme aprendemos por meio da mídia, da escola, de outras instituições comunitárias e do próprio meio familiar ${ }^{(16)}$.

Esse imaginário social em relação às drogas parece estar relacionado à visão proibicionista que perdura em nossa sociedade. O consumo de drogas ainda é visto como um problema de segurança pública, sendo considerado um ato delituoso que gera violência(17).

Por outro lado, o estudo também mostra que a experiência de consumo de drogas, inicialmente, pode proporcionar ao ser humano alguma forma de prazer:

[...] E aí a preocupação maior é justamente isso, que as drogas oferecem muitas coisas boas para os adolescentes, que eles acham que são boas, quando na verdade o futuro para quem se inicia mexendo com drogas, eu não digo nem cadeia, é morte. (Hebe) 
Parece um contrassenso, mas o estudo nos mobilizou a reconhecer que o consumo de drogas, visto segundo a ótica da promoção de prazer, poderá contribuir para a produção de sentido de vida e de relação. Entendemos que se a relação do ser humano com a droga apenas lhe gerasse danos, ele não a manteria ao ponto de estabelecer um vínculo tão forte, chegando ao estado de dependência.

A descrição do participante Hebe nos chamou a atenção para a ambiguidade da percepção humana em relação aos fenômenos sociais. A droga ora pode ser "boa", ora pode ser "ruim", uma vez que o consumo habitual pode trazer danos ao organismo e prejudicar até mesmo as relações sociais das pessoas ${ }^{(18)}$.

Nesse contexto de intensas mudanças e adaptação aos padrões sociais, o ser humano vivencia sentimentos de incapacidade e angústia, pois há uma valorização do ter em detrimento do ser, da cultura do corpo com seus padrões de beleza que nem sempre se consegue alcançar e da busca por soluções rápidas para seus problemas ${ }^{(19)}$.

Além disso, a própria condição existencial do ser humano e o reconhecimento de sua finitude provocamIhe sofrimentos. Merleau-Ponty afirma que o sonho da humanidade é conceber uma "eternidade de vida", ou seja, o ser humano não consegue lidar com a finitude, por isso classifica o tempo em passado, presente e futuro na esperança de que sempre haja um porvir. No entanto, de acordo com o filósofo, só existe, de fato, o "aqui e agora", que tem a ver com o corpo perceptivo, entendido como uma dimensão de nosso ser ${ }^{(11)}$.

Mediante a temporalidade, o ser humano vivencia experiências na relação com o mundo, com o outro e consigo mesmo. No momento em que dialogamos nos unimos aos outros seres humanos, há a reciprocidade, o que permite afirmarmos que participamos da vida de outrem ${ }^{(20)}$. Assim sendo, o momento em que um grupo se reúne para consumir droga pode significar uma experiência dialógica e de reciprocidade na condição de pares.

O ser humano tem em sua essência a necessidade de sentar-se à mesa e partilhar não somente o alimento, mas o conviver e o dialogar ${ }^{(20)}$. Todavia, na sociedade capitalista em que vivemos, essa comensalidade vem se perdendo, pois tudo se liquefaz muito rapidamente, inclusive as relações, que são curtas e utilitárias ${ }^{(19)}$. Diante desse contexto, sentimos a necessidade de resgatar o sentido humano da mesa, a convivialidade.

Portanto, a reflexão sobre o cuidado relacionado ao consumo de drogas nos faz enxergá-lo de forma multifacetada e nos permite viver a experiência do outro-eu-mesmo, entendendo que não há como classificar essa prática como "boa” ou "má”, uma vez que cada pessoa poderá vivenciar a experiência de uma forma singular. Desse modo, o cuidado também deverá acontecer por meio de experiências dialógicas que favoreçam a construção de relações de afeto e reciprocidade tanto no ambiente familiar como no escolar.

\section{Expressão sensível diante do fenômeno "consumo de drogas"}

Esta categoria está sustentada na noção merleau-pontyana sobre a experiência sensível, descrita a partir de seus estudos fenomenológicos acerca das vivências dos sentimentos ou mundo da vida(11).

A descrição de uma participante revela seu sentimento de tristeza ao configurar o consumo de drogas como elemento determinante da morte de adolescentes. Ela personifica a substância psicoativa (droga) como um ser em si, capaz de tirar a vida de alguém, de fazer com que filhos, ainda jovens, percam suas vidas antes da morte de seus pais: 
Eu fico muito triste! Porque as pessoas... eu vejo umas crianças socadas no meio de drogas, perdendo a vida direto por causa de droga...eu me sinto muito triste por isso, não é por causa de outra coisa, porque antigamente era assim, os filhos enterravam os pais e hoje em dia os pais estão enterrando os filhos por causa das drogas, porque as drogas estão matando com tudo. (Zeus)

No entanto, evidenciamos em nossa pesquisa que, no contexto do consumo de drogas, a pessoa tem sido colocada entre parênteses e o foco da atenção voltado à droga em si. As drogas são vistas como vilãs, sendo capazes de "produzirem sofrimento e morte" daqueles que as consomem, e a família, em função dos laços afetivos com seus integrantes, sente-se corresponsável por suas atitudes e culpada quando eles estabelecem uma relação habitual com drogas ${ }^{(21)}$.

Nessa perspectiva, a descrição de Zeus faz perceber que a família associa a droga à violência - tese incorporada ao imaginário social mediante um discurso moralista que orienta a expressão de juízo de valor, que é sempre negativo e gerador de estigma. Este fato tem a ver com a visão sociocultural posta em relação à droga como objeto de destruição familiar, o que reforça o pensamento merleau-pontyano de que, no universo cultural, as teses incorporadas mobilizam sentimentos e condutas humanas ${ }^{(11)}$.

Dessa forma, de acordo com Merleau-Ponty, existem dois mundos entrelaçados em nossa experiência, 0 "mundo dos sentimentos" e o "mundo da cultura". O que sentimos está relacionado tanto com algo que nos é humano e inerente como, também, com o que aprendemos no meio cultural ${ }^{(11)}$.

Portanto, o consumo de drogas precisa ser pensado não com o foco na substância em si, mas como uma experiência fenomênica do ser humano, que é mobilizada tanto em sua dimensão sensível como na sociocultural que o entorna. Não podemos considerar que existe total relação entre droga e violência.

As descrições, a seguir, revelam que os diversos sentimentos dos participantes do estudo em relação ao consumo de drogas podem ser mobilizados pela forte influência do modelo proibicionista ainda vigente, que propõe a eliminação das drogas consideradas ilícitas, uma vez que altera a ordem social:

É difícil explicar, mas é muito doloroso para mim. É a pior coisa que existe, o pior problema que a família pode ter é isso aí, drogas. (Cronos)

Eu... eu temo pelos jovens que estão se acabando, se destruindo, essa palavra, droga, já traz terror. (Artémis)

O uso de droga é ..., o certo é não usar, não é? Eu tenho pena de quem usa. (Ares)

Fala-se em droga, a gente já fica preocupada, já vem falar... meu Deus! Principalmente quando vê assim crianças. (Perséfone)

Na perspectiva de lidar com as diversas relações que a pessoa estabelece com a droga, considerando a singularidade de cada ser humano, surge uma nova forma de abordagem: a estratégia de Redução de Danos (RD), que parte do princípio de que não podemos saber o padrão de consumo de determinada substância mediante suas propriedades farmacológicas, mas por meio da relação entre a droga, o sujeito e o meio social(22).

Como tal, as drogas passaram a ser consumidas por todas as camadas sociais, ao ponto de passarem a ser vistas como mercadorias que oferecem grande poder econômico(22). Portanto, as ações de "guerra às drogas" não se dirige à substância, mas aos produtores, comerciantes e consumidores, que possuem interesses econômicos atrelados; têm sido deflagradas como instrumento legitimador de perseguição às pessoas de condições econômicas menos favorecidas ${ }^{(23)}$. 
Nesse contexto, a visão capitalista moderna pretende adequar os seres humanos aos padrões sociais estabelecidos, no intuito de que eles não possam ir de encontro à opinião dos outros ${ }^{(19)}$. A ideia proibicionista ainda encontra-se implicada nos discursos dos sujeitos, sendo difícil desconstruir essa visão que a própria mídia procura enfocar como a solução para a questão do consumo de drogas.

A descrição de uma participante revela o seu sentimento de impotência diante da necessidade de cuidado do sobrinho que consome drogas de forma habitual, o que a deixa bastante apreensiva. Destaca que a convivência com ele gera sofrimento não apenas para ela, mas para outras pessoas da família:

A gente fica muito apreensiva, tentamos ajudar e não estamos tendo meios, porque na minha família mesmo, tem um sobrinho que é usuário e a gente está sofrendo muito, principalmente minha mãe, está se acabando, é terrível, para quem passa mesmo pelo momento é terrível! (Ares)

A descrição mostra que o sofrimento vivenciado pela família decorre não somente do fato de o familiar consumir drogas, mas da falta de suporte à família na situação, o que nos remete à necessidade de se planejar e implementar ações efetivas no âmbito do território que inclua a família em sua convivialidade com integrantes que experimentam a condição.

Chamaram a nossa atenção as descrições que revelaram sentimentos de medo e preocupação dos participantes, ao refletirem sobre a possibilidade de um filho vir a tornar-se consumidor de drogas. Nesse momento, a primeira alternativa que conseguem visualizar é discorrer para o filho sobre os efeitos e danos a que estaria sujeito. Vejamos as descrições:

Penso logo no meu filho que está pequeno; então, a única coisa que eu posso fazer é instrui-lo, contar a realidade das drogas para ele poder não cair nessa, como muitos caíram [...]. (Perséfone)

A gente vê as crianças hoje em dia se envolvendo com drogas... falo assim: meu Deus, poderia ser meu filho, poderia ser minha filha, não é? A gente já fica assim pensando, preocupada, já se coloca no lugar dos pais [...].(Ares)

Essa preocupação por parte da família faz sentido, na medida em que se convencionou que ela é a principal instituição social responsável pela construção moral dos filhos, cabendo-lhe o compromisso de formar cidadãos que tenham comportamentos coerentes com a cultura social ${ }^{(24)}$. Se, por exemplo, uma mãe não se dispuser a esse papel em relação ao filho, estará sujeita a julgamento social como sendo irresponsável, o que pode resultar em sentimento de culpa e ansiedade.

Nesta perspectiva, ocorreu-nos a reflexão de que o medo pode não consistir apenas pela preocupação com o sofrimento do outro, mas por um cuidado de si, de sua reputação social. Além disso, o envolvimento habitual de uma pessoa com drogas, possivelmente, implicará em afetamento ao contexto familiar. No entanto, o homem em sua essência é cuidado e cuida de tudo o que pertence à existência: do mundo, das coisas do mundo, de si mesmos e dos outros homens ${ }^{(22)}$.

É a nossa humanidade que nos move ao cuidado e tem a ver com o sentimento de coexistência. Ainda que não tenhamos a experiência interna que o nosso semelhante está vivendo, quando compartilhamos sentimentos e atitudes na relação com ele nos ocorre uma vivência intercorporal ${ }^{(11)}$. Esse pensamento fortalece a abordagem contemporânea das políticas de saúde mental cuja lógica é o cuidado humano em sua integralidade, o que inclui 
o reconhecimento da importância e incentivo à estratégia de redução de danos, o que envolve a valorização da dimensão social e da sensibilidade do consumidor de drogas.

\section{CONCLUSÃO}

O estudo revelou a presença de teses instituídas no meio social em relação ao consumo de drogas relacionada à visão objetivista, já que os familiares enxergam a droga como uma "coisa em si", capaz de sempre causar danos. Também demonstrou um novo olhar sobre o consumo de drogas como algo que causa prazer e, portanto, beneficia o homem.

Ao nos remetermos ao consumo de drogas, percebemos que apareceram descrições relacionadas à dimensão sensível dos participantes, uma vez que eles relataram sentimentos como dor, terror, medo. Esses sentimentos são mobilizados pelo que os participantes aprenderam no meio cultural de que a droga é algo "ruim", "que causa destruição". Dessa forma, percebemos que a dimensão sensível e a sociocultural estão entrelaçadas, uma remete a outra.

Desse modo, o estudo revela que o cuidado relacionado ao consumo de drogas ocorre por meio de relações afetivas desenvolvidas em diferentes ambientes, ao mesmo tempo em que desafia a família e a escola a tornaremse espaços mais atrativos e dialógicos, de acolhimento e de construção coletiva de projetos de vida mais saudáveis. Por outro lado, reconhece a importância e incentivo à estratégia de redução de danos como fundamento para o respeito à pessoa que consome drogas.

Nesse contexto, os resultados desta pesquisa evidenciam a necessidade de desconstrução das teses existentes relacionadas ao consumo de drogas no meio social, demonstrando a necessidade de implementação de atividades de educação em saúde direcionadas aos familiares de adolescentes, principalmente no ambiente escolar. Acreditamos que este estudo conseguiu alcançar o seu objetivo e os seus resultados são de extrema relevância para a implementação de estratégias na área da saúde e educação direcionadas ao consumo de drogas.

\section{REFERÊNCIAS}

1. Faria Filho EA, Queiros OS, Medeiros M, Rosso CFW, Souza MM. Concepções sobre drogas por adolescentes escolares. Rev Bras Enferm [Internet]. 2015 [acesso em: 01 out. 2018];68(3):517-23. Disponível em: https://doi.org/10.1590/0034-7167.2015680320i. 2. Costa AG, Camurça VV, Braga JM, Tatmatsu DIB. Drogas em áreas de risco: o que dizem os jovens. Physis [Internet]. 2012 [acesso em: 01 out. 2018];22(2):803-19. Disponível em: https://doi.org/10.1590/\$0103-73312012000200021.

3. Zeitoune RCG, Ferreira VS, Silveira HS, Domingos AM, Maia AC. O conhecimento de adolescentes sobre drogas lícitas e ilícitas: uma contribuição para a enfermagem comunitária. Esc Anna Nery [Internet]. 2012 [acesso em: 01 out. 2018];16(1):57-63. Disponível em: https://doi.org/10.1590/S1414-81452012000100008.

4. Horta RL, Horta BL, Costa AWN, Prado RR, Oliveira-Campos M, Malta DC. Lifetime use of illicit drugs and associated factors among Brazilian schoolchildren, National Adolescent School-based Health Survey (PeNSE 2012). Rev Bras Epidemiol [Internet]; 2014 [acesso em: 01 out. 2018];17 supl. 1:31-45. Disponível em: https://doi.org/10.1590/1809-4503201400050004.

5. Camarotti AC, Kornblit AL, Di Leo PF. Prevención del consumo problemático de drogas en la escuela: estrategia de formación docente en Argentina utilizando TIC. Interface (Botucatu) [Internet]. 2013 [acesso em: 01 out. 2018];17(46):695-703. Disponível em: https://doi.org/10.1590/S1414-32832013005000023.

6. Machado LV, Boarini ML. Políticas sobre drogas no Brasil: a estratégia de redução de danos. Psicol. cienc. prof. [Internet]. 2013 [acesso em: 01 out. 2018];33(3):580-95. Disponível em: https://doi.org/10.1590/S1414-98932013000300006.

7. Forteski R, Faria JG. Estratégias de Redução de Danos: Um exercício de Equidade e Cidadania na Atenção a Usuário de Drogas. Revista de Saúde Pública de Santa Catarina [Internet]. 2013 [acesso em: 01 out. 2018];6(2):78-91. Disponível em: http://revista.saude.sc.gov.br/index.php/inicio/article/view/169. 
8. Elicker E, Palazzo LS, Aerts DRGC, Alves GG, Sheila C. Uso de álcool, tabaco e outras drogas por adolescentes escolares de Porto Velho-RO, Brasil. Epidemiol Serv Saude [Internet]. 2015 [acesso em: 01 out. 2018];24(3):399-410. Disponível em:

http://ref.scielo.org/mj36hc.

9. Fuentes MC, Alarcón A, García F, Gracia E. Consumo de alcohol, tabaco, cannabis y otras drogas en la adolescencia: efectos de la familia y el barrio. Annals of Psychology [Internet]. 2015 [acesso em: 01 out. 2018];31(3):1000-7. Disponível em: https://doi.org/10.6018/analesps.31.3.183491.

10. Freires IA, Gomes EMA. O papel da família na prevenção ao uso de substâncias psicoativas. Revista Brasileira de Ciências da Saúde [Internet]. 2012 [acesso em: 01 out. 2018];16(1):99-104. Disponível em:

http://www.periodicos.ufpb.br/ojs2/index.php/rbcs/article/view/10899.

11. Merleau-Ponty M. Fenomenologia da percepção. Moura CA, tradutor. 3ạ ed. São Paulo: Martins Fontes; 2015.

12. Barreto AP. Terapia Comunitária: passo a passo. 4a ed. Fortaleza: Gráfica LCR; 2008.

13. Merleau-Ponty M. A prosa do mundo. São Paulo: Cosac \& Naify; 2012.

14. Guerrero-Castañeda RF, Menezes TMO, Ojeda-Vargas MG. Características de la entrevista fenomenológica en investigación en enfermería. Rev Gaucha Enferm [Internet]. 2017 [acesso em: 01 out. 2018];38(2):e67458. Disponível em:

https://doi.org/10.1590/1983-1447.2017.02.67458.

15. Sena ELS, Gonçalves LHT, Granzotto MJM, Carvalho PAL, Reis HFT. Analítica da ambiguidade: estratégia metódica para a pesquisa fenomenológica em saúde. Rev Gaucha Enferm [Internet]. 2010 [acesso em: 01 out. 2018];31(4):769-75. Disponível em: https://doi.org/10.1590/S1983-14472010000400022.

16. Sena ELS, Boery RNO, Carvalho, PAL, Reis HFT, Marques, AMN. Alcoolismo no contexto familiar: um olhar fenomenológico. Texto contexto - enferm. [Internet]. 2011 [acesso em: 01 out. 2018];20(2):310-8. Disponível em: https://doi.org/10.1590/S010407072011000200013.

17. Araújo ATS, Silva JC, Oliveira FM. Infância e adolescência e redução de danos/intervenção precoce: diretrizes para intervenção. Psicologia Argumento (Impresso) [Internet]. 2013 [acesso em: 01 out. 2018];31(72):145-54. Disponível em:

https://periodicos.pucpr.br/index.php/psicologiaargumento/article/view/20453.

18. Faria Filho EA. Perfil do consumo de álcool e drogas ilícitas entre adolescentes escolares de uma capital brasileira. SMAD, Rev. Eletrônica Saúde Mental Álcool Drog. [Internet]. 2014 [acesso em: 01 out. 2018];10(2):78-84. Disponível em:

https://doi.org/10.11606/issn.1806-6976.v10i2p78-84.

19. Baumam Z. Vida Líquida. 2a ed. Rio de Janeiro: Zahar; 2009.

20. Boff L. Virtudes para um outro mundo possível. Volume III: Comer e beber juntos e viver em paz. Petrópolis: Vozes; 2006.

21. Maciel SC. A importância da família na prevenção às drogas. In: Barros DR, Espínola LL, Serrano RMSM, organizadores.

Toxicomania: prevenção e intervenção. João Pessoa: Editora Universitária da UFPB; 2008. p. 31-43.

22. Sodelli M. A abordagem proibicionista em desconstrução: compreensão fenomenológica existencial do uso de drogas. Cien Saude Colet [Internet]. 2010 [acesso em: 01 out. 2018];15(3):637-44. Disponível em: https://doi.org/10.1590/S141381232010000300005.

23. Rocha AP. Proibicionismo e a criminalização de adolescentes pobres por tráfico de drogas. Serv. Soc. Soc. [Internet]. 2013 [acesso em: 01 out. 2018];(115):561-80. Disponível em: https://doi.org/10.1590/s0101-66282013000300009.

24. Sena ELS, Reis HFT, Carvalho PAL, Souza VS. A intersubjetividade do cuidar e o conhecimento na perspectiva fenomenológica. Rev Rene [Internet]. 2011 [acesso em: 01 out. 2018];12(1):181-8. Disponível em: http://periodicos.ufc.br/rene/article/view/4183. 